The results of our present trial suggest that there may be little important difference between three-day and 10-day courses of amoxycillin. Within the sample of patients we studied a number undoubtedly had a self-limiting disease which required no antibiotic treatment at all. There may also have been a group for whom three-day or even 10-day treatment would have been inadequate. We cannot, in retrospect, identify any of these groups. Nevertheless, most of the improvement in symptoms clearly occurs in the first few days. We suggest that patients with otitis media who need antibiotics should be treated for three days only and then reassessed at about the fifth or sixth day after starting treatment. Only those whose rate of improvement is unsatisfactory should have antibiotics for longer. The relatively high frequency of hearing loss in both groups three months after an episode is not unexpected and emphasises the need to follow up these patients until hearing returns to normal. We have shown that this form of management is practicable in British general practice and could save the Health Service over $£ 1$ million annually in antibiotic costs without reducing the standard of care. Whether overall savings would result from this policy can be determined only by a full cost-benefit analysis, which we have not attempted.

We thank Mr J B Booth and Mr S J Abramovich, who acted as independent assessors of the audiograms. We gratefully acknowledge the generous financial support from the special trustees of the London Hospital, without whom this trial could not have taken place. We also thank Messrs Edwin Burgess for sensible graduated 2-5 ml plastic spoons and Messrs Bencard for trial supplies.

\section{References}

${ }^{1}$ Howie VM. Acute and recurrent otitis media. In: Jaffe B, ed. Hearing los in children. Baltimore: University Park Press, 1977.

2 Anonymous. Otitis media. FAMA 1980;244:2603.

${ }^{3}$ Royal College of General Practitioners, Office of Population Censuses and Surveys, Department of Health and Social Security. Morbidity statistics from general practice 1971-2. London: HMSO, 1979.

- Anonymous. Antibiotics for otitis media. Br Med f 1976;ii:1407.

5 Charlton CAC, Crowther A, Davies JG, et al. Three-day and 10-day chemotherapy for urinary tract infections in general practice. $\mathrm{Br} \mathrm{Med} \mathcal{F}$ 1976 ; : $124-6$.

- Fang LST, Tolkoff-Rubin HE, Rubin RH. Efficacy of single dose and conventional amoxycillin therapy in urinary tract infection localised by the antibody-coated bacteria technic. $N$ Engl f Med 1978;298:413-6.

${ }^{7}$ Becker MH, Drachman RH, Kirscht JP. Motivations as predictors of health behaviour. Health Services Rep 1972;87:852-61.

8 Charney E, Bynum R, Eldredge D, et al. How well do patients take oral penicillin ? A collaborative study in private practice. Paediatrics 1967 40:188-95.

- Halstead C, Lepow ML, Balassanian H, Emmerich J, Wolinsky E. Otitis media. Clinical observations, microbiology, and evaluation of therapy. Am $\mathcal{F}$ Dis Child 1968;115:542-51.

10 Van Buchem FL, Dunk JHM, Van't Hof MA. Therapy of acute otitis media: myringotomy, antibiotics or neither? Lancet 1981 ;ii:883-7.

11 Froom J, Mold J, Culpepper L, Boisseau V. The spectrum of otitis media in family practice. $\mathcal{F}$ Fam Pract 1980;10:599-605.

12 Fry J. Profiles of common diseases. 1966, London \& Edinburgh: E \& S Livingstone 1966.

13 Thomson J, Meistrup-Larsen KI, Sorenson H, Larsen PK, Mygind N. Penicillin and acute otitis: short and long-term results. Ann Otol Rhino Laryngol 1980;89 suppl 68:271-4.

14 Diamant M, Diamant B. Abuse and timing of use of antibiotics in acute otitis media. Arch Otolaryngol 1974;100:226-32.

(Accepted 24 February 1982)

\title{
Survival and desferrioxamine in thalassaemia major
}

\author{
B MODELL，E A LETSKY，D M FLYNN， R PETO，D J WEATHERALL
}

\begin{abstract}
A small randomised trial and observation of all patients homozygous for beta-thalassaemia in Britain born in or before 1963 indicated that those patients who had received average weekly doses of more than $4 \mathrm{~g}$ of desferrioxamine over the previous few years were less likely to die in the near future than were patients of similar ages who had received less, or no, desferrioxamine.
\end{abstract} Department of Obstetrics and Gynaecology, University College
Hospital, London WC1

B MODELL, MB, PHD, honorary consultant in perinatal medicine

Hospital for Sick Children, Great Ormond Street, London WC1N 3JH E A LETSKY, MB, MRCPATH, honorary consultant

Royal Free Hospital, London NW3 2QG

D M FLYNN, MD, MRCP, consultant paediatrician

Clinical Trial Service Unit, Nuffield Department of Clinical Medicine, Radcliffe Infirmary, Oxford OX2 6HE

$R$ PETO, MA, MSC, reader in cancer studies

MRC Molecular Haematology Unit, Nuffield Department of Clinical Medicine, University of Oxford, John Radcliffe Hospital, Oxford OX3 9DU

D J WEATHERALL, FRCP, FRCPATH, FRS, Nuffield professor of clinical medicine and honorary director, MRC Molecular Haematology Unit

\section{Introduction}

Patients homozygous for $\beta$-thalassaemia die of anaemia in infancy unless regularly transfused. Each unit of blood contains about $200 \mathrm{mg}$ of iron, however, so that patients treated only by regular transfusion usually die in their second or third decade from the chronic effects of iron deposited in the myocardium. Early attempts to control iron overload by daily intramuscular injection of the iron-chelating agent desferrioxamine showed that iron excretion would balance iron input only when the concentration of iron in the body was undesirably high. ${ }^{1-4}$ When the drug is administered by slow subcutaneous infusion, however, a given dose is more effective and larger doses may be used; hence this approach may more successfully control iron overload. ${ }^{5-9}$ Regular parenteral infusion of desferrioxamine is cumbersome and expensive, and it is therefore desirable to know whether iron-chelation treatment measurably alters the survival of patients with transfusion-dependent $\beta$-thalassaemia.

In Britain children with $\beta$-thalassaemia major were first given desferrioxamine in 1962, and since 1967 some have received daily intramuscular injections amounting to an average of about $4 \mathrm{~g}$ a week, in the hope of postponing or even preventing cardiac death. ${ }^{34}$ The numbers of children treated with desferrioxamine have increased steadily, though many at first received the drug only intravenously at the time of transfusion or in infrequent short intramuscular courses that would not be expected to achieve a net iron balance in a transfusion-dependent child. In the late $1970 \mathrm{~s}$, as a result of the gradual accumulation of evidence for its value, practically all patients in Britain had begun regular subcutaneous infusions of desferrioxamine.

We present details of drug doses and survival for all patients 
homozygous for $\beta$-thalassaemia in Britain since desferrioxamine began to be used. Our chief aim was to determine whether those patients who had been given the drug regularly for several years were any less likely to die in the immediate future than were patients of similar age who had received less, or no, desferrioxamine.

\section{Patients}

Patients with thalassaemia who are regularly transfused do not die of iron overload before 10 years of age. Hence, and because desferrioxamine became available for clinical use in Britain only in 1963, we followed up to the end of 1980 all children with thalassaemia major who were born in or before 1963 and who were alive and resident in Britain on their tenth birthday in order to relate treatment to outcome.

For the 92 such patients dates of birth and death and number of grams of desferrioxamine given in each calendar year from 1963 to 1978 were abstracted from medical records. (These data are listed in an appendix, which along with a statistical appendix may be obtained on request from DJW.) The patients were located in the following three ways.

(1) In 1967 we searched the diagnostic indexes of all London hospitals that treat children and investigated all mentions of thalassaemia. Additional informal investigations over the next 10 years ensured complete coverage of the London area, where most Mediterranean immigrants live.

(2) In 1975 members of the British Paediatric Association were circulated asking for brief details of all living children with thalassaemia. We think that full co-operation was achieved, and a subsequent approach to all members of the British Society for Haematology yielded no cases that had not been ascertained through the first two channels.

(3) Finally, the Registrar General provided a list of all deaths with any mention of thalassaemia in the years 1963-77. Informal information on such deaths is now also provided by the UK Thalassaemia Society (a patients' and parents' association).

If, as we think likely, our coverage was complete or virtually complete then no bias was introduced by selecting patients because they were alive in 1975 or because they had died and been registered, and we had a representative sample of the natural history of the disease in Britain. However they were ascertained, all 92 patients (including two who subsequently emigrated) were fully documented with respect to dosage of desferrioxamine and survival. In most cases we also abstracted details of transfusion scheme, infections, splenectomy, and development of symptoms of iron overload, such as stunting of growth, endocrinopathy, or cardiac failure; but these are not directly relevant to this report. Nineteen of the 92 patients were randomised in 1966-7 between a control group of 10 patients and a desferrioxaminetreated group of nine. ${ }^{310}$ Though small, these two groups were interesting because comparison was definitely unbiased and there was a very pronounced contrast in the dosage of the drug given to the two groups, the treated patients having received about $4 \mathrm{~g}$ weekly for over 10 years.

The remaining 73 patients were not in the randomised trial and the decision to give desferrioxamine depended on the paediatrician. Many were not given the drug at all for at least as long as their health appeared sound, and some received inadequate doses, usually less than $1 \mathrm{~g} /$ week given in the blood at transfusion; but with the passage of time an increasing number-even when in good health-received larger doses nearly comparable to those used in the randomised trial, though for fewer years.

It is obviously more difficult to interpret non-randomised data than the results of a randomised trial. The only important bias that we knew of in the non-randomised group was that as patients who received little or no desferrioxamine developed serious symptoms of iron toxicity they tended to be given very large doses of the drug in the year or so before their death, and unless this tendency is allowed for it might misleadingly appear that starting the drug is extremely dangerous. A preliminary survey of the complete data showed no significant differences in transfusion scheme or splenectomy state between the group who had received little or no desferrioxamine and the group who had received daily intramuscular injections. We therefore doubt whether physicians who preferred to use the drug were either more or less vigorous or skilled in other aspects of their general management of these children, or whether they were influenced in their decision to use or not use the drug by any clinical observations that would be relevant to future cardiac deaths in apparently healthy patients with thalassaemia. If this were the case simple comparison of mortality in the patients who had received regular treatment with the drug and those who had not should yield a relatively unbiased measure of the benefit of desferrioxamine, even though allocation to treatment was not properly randomised.

\section{Methods}

At the beginning of each year (1963-80) we computed for each patient a "mean desferrioxamine index." This was the mean weekly dose of the drug that the patient had received in the first five of the six preceding years (fig 1). The mean index was then related to the

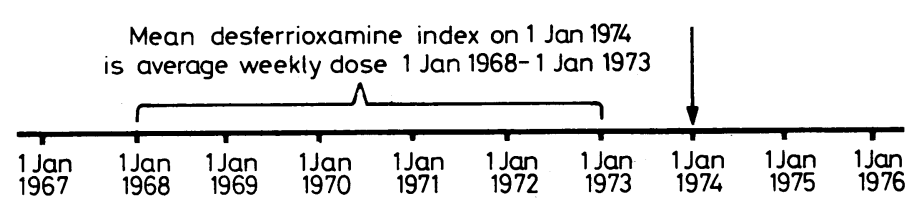

FIG 1-Example of computation of mean desferrioxamine index on 1 January 1974 .

likelihood of death in the following year using the statistical methods described in the appendix (with correction for continuity). Three points should be made about this index. Firstly, it ignores desferrioxamine given in the immediate past year for terminally ill patients. Secondly, it assesses usage of the drug over a relatively long period, because iron damage to the myocardium is presumably a slow process. Thirdly, it changes with time-for example, for a patient who received no desferrioxamine until 1 January 1970 and then started with $5 \mathrm{~g}$ weekly the index would be zero on 1 January $1971,1 \mathrm{~g}$ weekly on 1 January 1972, etc, rising to its final value of $5 \mathrm{~g} /$ week only on 1 January 1975. Fourthly, because of the tendency for the drug to be used more widely patients aged $15-20$ in 1980 were likely to have a higher mean index than were patients aged 15-20 in, say, 1970; hence any general improvement in medical care over the 10 years which reduced the likelihood of death may masquerade as an advantage of desferrioxamine when we come to interpret the non-randomised data. Nevertheless, this bias is less severe than might be expected because the age of the immigrant groups among whom this disease occurs is such that only three deaths from iron overload occurred in the early period 1963-9, while the remaining 22 deaths among the nonrandomised patients occurred in 1970-80.

Statistical-All p values cited here are "one tailed"-that is, they estimate the probability of at least as great a difference in mortality in favour of desferrioxamine appearing by chance alone. Doubling the 1p values gives the more usual two-tailed $p$ values, which estimate the probability of at least as great a difference in one direction or the other arising by chance alone.

\section{Results}

\section{OVERALL SURVIVAL, IRRESPECTIVE OF TREATMENT}

By pooling all the available data we used standard methods ${ }^{11}$ to construct a life table which describes the age-specific mortality of the entire group of patients (fig 2).

\section{RANDOMISED TRIAL}

In 1966-7 at the Hospital for Sick Children, London, 20 patients thought to have thalassaemia major were randomised between a regimen including an average of about $4 \mathrm{~g}$ desferrioxamine weekly and a control regimen not including the drug. In one patient (allocated to the drug, and who remained well) the diagnosis was later changed to thalassaemia intermedia, leaving 10 control patients (born on average in 1959), six of whom had died by 1980 , and nine treated patients (born on average in 1960), only one of whom had died by 1980. (The patient who died differed from the rest of the treated group in having moved to another hospital four years before his death, where he received less frequent transfusions than the other patients; he also had diabetes.) All seven deaths occurred in patients with a history of iron overload. The results of the statistical analysis (table I) were promising but not conclusive $(1 \mathrm{p}=0.04$ by Fisher's exact test; $1 \mathrm{p}=0.07$ by the age-standardised analysis (table $\mathrm{I}$ and statistical appendix)). This might have been due to the small size of the group 
and the fact that the treated patients had an average date of birth of 1960 and so were only just entering the period of greatest risk (see fig 2). If with continued follow-up their survival remained good for five more years (from 1980), this would provide stronger evidence for a real beneficial effect of desferrioxamine.

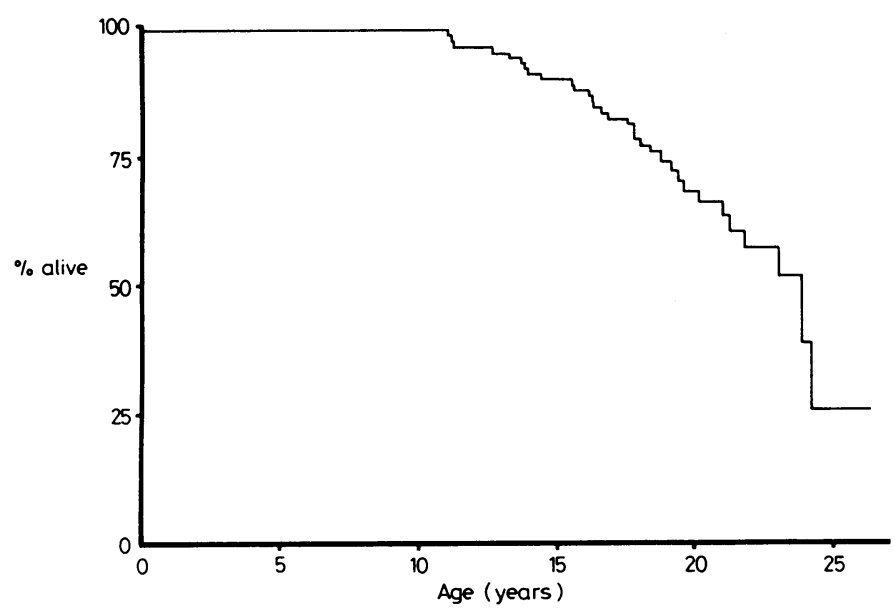

FIG 2-Life-table estimate ${ }^{11}$ of probability of survival at various ages. (All patients irrespective of treatment.)

TABLE I-Age-standardised analysis of relevance of allocated treatment to risk of death in randomised trial at Hospital for Sick Children, London, 1966-80. (All seven deaths occurred in patients with a history of iron overload)

\begin{tabular}{|c|c|c|c|c|}
\hline \multirow[b]{2}{*}{ Group } & \multicolumn{2}{|c|}{ Deaths } & \multirow{2}{*}{$\begin{array}{l}\text { Ratio } \\
\mathrm{O}: \mathrm{E}\end{array}$} & \multirow{2}{*}{$\begin{array}{l}\text { Normalised } \\
\text { test statistic } \\
\text { for trend* }\end{array}$} \\
\hline & Expected (E) & Observed $(\mathrm{O})$ & & \\
\hline $\begin{array}{l}\text { Control ( } 10 \text { patients) } \\
\text { Treated ( } 9 \text { patients) }\end{array}$ & $\begin{array}{l}3 \cdot 47 \\
3 \cdot 53\end{array}$ & $\begin{array}{l}6 \\
1\end{array}$ & $\left.\begin{array}{l}1.7 \\
0.3\end{array}\right\}$ & $=1.55 ; 1 \mathrm{p}=0.07$ \\
\hline Both groups & $7 \cdot 00$ & 7 & 1.0 & \\
\hline
\end{tabular}

*With correction for continuity. Cited $\mathrm{p}$ value for one-tailed test of statistical significance.

\section{WHOLE GROUP OF 92 PATIENTS}

If desferrioxamine were wholly without effect on survival we might expect to find that among people of a given age the likelihood of death in the near future would be unrelated to the mean desferrioxamine index. Almost none of the patients in the non-randomised group achieved a mean index of $4 \mathrm{~g} /$ week, partly because many of them had not been receiving regular treatment for as long as those in the randomised trial, so that the results of the randomised trial cannot be compared directly with the non-randomised data. But the randomised and non-randomised data can be pooled to see whether there was any relation between increasing dosage of desferrioxamine and improved survival in the whole group of 92 patients. Subdividing the mean index as zero, up to 1 , up to 2 , up to 3 , and 3 or more $g$ /week and summating the expected numbers from each separate year of age (statistical appendix) we obtained the results shown in table II, in which a highly statistically significant trend is evident.

TABLE II-Age-standardised analysis of relevance of mean desferrioxamine index $(M D I)$ in first five of six preceding years to risk of death during coming year. All 92 patients (19 randomised +73 not)

\begin{tabular}{|c|c|c|c|c|}
\hline \multirow[b]{2}{*}{ MDI range } & \multicolumn{2}{|c|}{ Deaths } & \multirow{2}{*}{$\begin{array}{c}\text { Ratio } \\
\text { O:E }\end{array}$} & \multirow{2}{*}{$\begin{array}{l}\text { Normalised test } \\
\text { statistic for } \\
\text { trend* }\end{array}$} \\
\hline & Expected (E) & Observed (O) & & \\
\hline $\begin{array}{l}0 \\
\text { Up to } 1 \mathrm{~g} / \text { week } \\
\text { Up to } 2 \mathrm{~g} / \text { week } \\
\text { Up to } 3 \mathrm{~g} / \text { week } \\
3 \text { or more } \mathrm{g} / \text { week }\end{array}$ & $\begin{array}{l}8 \cdot 59 \\
8 \cdot 73 \\
3 \cdot 08 \\
2 \cdot 27 \\
9 \cdot 33\end{array}$ & $\begin{array}{c}13 \dagger \\
10 \\
5 \\
1 \\
3\end{array}$ & $\begin{array}{l}1.5 \\
1.1 \\
1.6 \\
0.4 \\
0.3\end{array}$ & $z=2.83 ; 1 \mathrm{p}=0.003$ \\
\hline Total & 32.00 & $32+$ & $1 \cdot 0$ & \\
\hline
\end{tabular}

With correction for continuity. Cited $p$ value for one-tailed test of statistical significance. Expected numbers of deaths (here, as in table I) were standardised for

single years of age,
+ Two deaths in patients with no history of iron overload.
Two of the 13 deaths among patients who had not been treated with desferrioxamine were not associated with iron overload, however, and arguably these were irrelevant to our assessment of the drug. Even when the analysis was repeated with these two deaths excluded, however, a highly significant trend remained $(z=2.58$ with correction for continuity; $1 \mathrm{p}=0.005$ ).

The choice of a six-year moving average to define the mean desferrioxamine index was made on prior theoretical grounds, independent of the actual data, but the exact number of years did not appear to be critical. For example, the statistical significance levels were, if anything, somewhat more extreme $(z=3 \cdot 21 ; 1 \mathrm{p}=0.0007)$ when a three-year moving average was used instead (so that the mean index was defined as the mean weekly dose in the first two of the three preceding years).

\section{Discussion}

The data available so far show significantly better survival among children for whom an average weekly dose of at least $3 \mathrm{~g}$ desferrioxamine was established, and, despite the various possibilities of bias that existed, the most plausible interpretation is that the treatment actually prevented or delayed several deaths. Theoretically there are two possible ways in which the drug might prevent disease due to iron overload. Firstly, on the assumption that disease is simply related to the total body iron load, the drug might protect simply by reducing this. If so, prolonged administration of high doses of desferrioxamine would presumably be needed to produce the requisite major change in iron load. Alternatively, considerably lower doses might in principle exert an antitoxic effect since desferrioxamine chelates the most labile, and therefore presumably the most toxic, iron fraction. Such an effect could be relatively independent of the total iron load and might be brought about by regular administration of relatively small doses. In both cases, however, treatment is likely to have to be given over at least a few years before any measurable benefit can be anticipated, for myocardial damage by iron is a chronic process and only slowly reversible, if it can be reversed at all.

Because of the uncertainty about the chief mechanisms of action of desferrioxamine theory alone cannot predict what will be an adequate dose. It is noteworthy that even among patients maintained for some years on average weekly doses of over $3 \mathrm{~g}$ three deaths occurred, all associated with iron overload, and such patients may also develop other abnormalities such as diabetes or growth disturbance. ${ }^{4}$ An important point is that the dose of desferrioxamine was not weight related in either the randomised or most of the non-randomised patients. In most patients the relative dose dropped steadily as the patients grew, so its effectiveness would be expected to decrease with age. For instance, in the randomised treated patients the range of doses was 15-28 $\mathrm{mg} / \mathrm{kg} /$ day at the start of the trial and $7-14 \mathrm{mg} / \mathrm{kg} /$ day six years later. If, as it appears, such treatment does have a substantial effect on survival the final dose was so small as to suggest that the drug may indeed exert an antitoxic effect by chelating the most toxic iron fraction in addition to its effect on body iron load.

Desferrioxamine at a dosage of $4 \mathrm{~g}$ /week may delay the onset of hepatic fibrosis ${ }^{3}$ and reduce the incidence of cardiac arrhythmias. ${ }^{12}$ Our data suggest that this dosage can also prolong life, but it is not clear whether death is substantially delayed by such treatment, because most deaths occur between the ages of 15 and 25 years and the patients that have been treated with this sort of regimen are as yet only at about their 20th year. Practically all patients now receive higher doses of desferrioxamine by regular subcutaneous infusion, however, and so it will not be possible by further study of this group of patients to establish the final life expectancy of children treated intramuscularly alone.

What should be the policy regarding the management of homozygous $\beta$-thalassaemia? It is now clearly established that using the newer techniques of the administration of desferrioxamine by subcutaneous infusion it is possible to achieve negative iron balance in older patients over a relatively long period and stabilise the body iron load of small children at a relatively low value. Moreover, there has been no evidence of tachy- 
phylaxis, and there is also preliminary evidence for improvement in organ function in patients treated in this way. ${ }^{13}$ Thus where possible affected children should presumably be treated with desferrioxamine using the subcutaneous infusion approach or, if this is not practicable, by administering the drug intramuscularly at the dose of at least the $15-28 \mathrm{mg} / \mathrm{kg} /$ day achieved at the beginning of the study by Barry et al. ${ }^{3}$ Also the progress of the children treated in this way should be monitored with respect to age at onset of puberty, liver iron loading and function, ${ }^{9}$ endocrine and cardiac function, ${ }^{14}{ }^{15}$ growth rate, and overall wellbeing. If really large effects on survival are produced by these more aggressive forms of chelation treatment they may hopefully be shown convincingly by simple comparison of future mortality with the data we report here. More moderate effects, however, might fail to be clearly recognised in such a non-random historical comparison and, of course, any general improvements in ancillary management may yield improved survival which is mistakenly attributed to infusions of desferrioxamine. Perhaps, however, these difficulties of interpretation will eventually be bypassed by introducing less troublesome methods of avoiding iron overload.

We gratefully record that we received $100 \%$ co-operation from the many clinicians looking after older thalassaemic patients in Britain. This work was supported by a Medical Research Council grant, and BM expresses appreciation of the personal help of Prince Sultan bin Abdulaziz, of Saudi Arabia, and the kindness of Madame Nouha and Sheikh Faisal Al-Hegelan.

The data and statistical appendices may be obtained on request from DJW.

\section{References \\ ${ }^{1}$ Sephton-Smith R. Iron excretion in thalassaemia major after administra- tion of chelating agents. Br Med $\mathcal{F} 1962$;ii:1577-80.}

2 Sephton-Smith $\mathrm{R}$. Chelating agents in the diagnosis and treatment of iron overload in thalassemia. Ann NY Acad Sci 1964;119:776-88.

${ }^{3}$ Barry M, Flynn DM, Letsky EA, Risdon RA. Long-term chelation therapy in thalassaemia major: effect on liver iron concentration, liver histology, and clinical progress. $\mathrm{Br}$ Med $\mathcal{F} 1974 ; \mathrm{ii}: 16-20$.

${ }^{4}$ Modell CB, Beck J. Long-term desferrioxamine therapy in thalassemia. Ann NY Acad Sci 1974;232:201-10

${ }^{5}$ Propper RD, Shurin SB, Nathan DG. Reassessment of the use of desferrioxamine B in iron overload. N Engl f Med 1976;294:1421-3.

6 Propper RD, Cooper B, Rufo RR, et al. Continuous subcutaneous administration of desferrioxamine in patient with iron overload. $N$ Engl f Med $1977 ; 297: 418-23$.

${ }^{7}$ Hussain MAM, Flynn DM, Green N, Hussein S, Hoffbrand AV. Subcutaneous infusion and intramuscular injection of desferrioxamine in patients with transfusional iron overload. Lancet 1976; :1278-80.

8 Pippard MJ, Callender ST, Letsky EA, Weatherall DJ. Prevention of iron-loading in transfusion dependent thalassaemia. Lancet 1978; ; 1178-81.

9 Modell CB. Advances in the use of iron-chelating agents for the treatment of iron overload. In: Brown EB, ed. Progress in hematology. Vol 11. New York and London: Grune and Stratton, 1979:267-312.

${ }^{10}$ Letsky EA. A controlled trial of long-term chelation in homozygous $\beta$ thalassemia. In: Bergsma D, Cerami A, Peterson CM, eds. Iron metabolism and thalassemia. National Foundation-March of Dimes. Birth Defects 1976;12:31-42.

11 Peto R, Pike MC, Armitage P, et al. Design and analysis of randomized clinical trials requiring prolonged observation of each patient. II. Analysis and examples. Br $\mathcal{F}$ Cancer $1977 ; 35: 1-39$.

12 Kaye SB, Owen M. Cardiac arrhythmias in thalassaemia major: evaluation of chelation treatment using ambulatory monitoring. $\mathrm{Br} \mathrm{Med} \mathcal{F} 1978$; : 342 .

${ }^{13}$ Hoffbrand AV, Gorman A, Graulicht M, et al. Improvement in iron status and liver function in patients with transfusional iron over-load with long term subcutaneous desferrioxamine. Lancet 1979; :947-9.

${ }^{14}$ Henry WL, Nienhuis AW, Wiener M, Millar DR, Canale VC, Piomelli S. Echocardiographic abnormalities in patients with transfusion-dependent anemia and secondary myocardial iron deposition. Am $\mathcal{F}$ Med 1978; $64: 547-55$.

${ }^{15}$ Weatherall DJ, Clegg JB. The thalassaemia syndromes. 3rd ed. Oxford: Blackwell Scientific Publications, 1981.

(Accepted 8 fanuary 1982)

\section{SHORT REPORTS}

\section{Importance of short-term changes in glycosylated haemoglobin}

Formation of glycosylated haemoglobin (haemoglobin $A_{1}$ ) has been considered to occur slowly within the erythrocyte at a rate dependent on the ambient blood glucose concentration. The amount formed has therefore been thought to reflect the average blood glucose concentration over the previous two to three months. Recent reports have shown, however, that acute reversible changes in glycosylation may occur and are related to short-term fluctuations in blood glucose concentration. ${ }^{1-3}$ These reports raise important questions concerning the validity of measurements of haemoglobin $A_{1}$ as indicators of longterm diabetic control.

We examined the magnitude of these reversible changes, and their relation with the total proportion of haemoglobin $A_{1}$ and blood glucose concentration, in an attempt to assess their importance in clinical practice.

\section{Patients, methods, and results}

The method for measuring the reversible, or labile, fraction (difference in percentage) of haemoglobin $A_{1}$ was established by comparing the time course of changes in the percentage of haemoglobin $A_{1}$ due to dissociation of this fraction during incubation for 24 hours in glucose-free medium $(0.9 \%$ saline) at $4^{\circ} \mathrm{C}, 22^{\circ} \mathrm{C}$, and $37^{\circ} \mathrm{C}$. Blood was drawn from six diabetic inpatients and two normal subjects and was placed into EDTA. The proportion of haemoglobin $A_{1}$ was assayed by a microcolumn method modified from that of Kynoch and Lehmann. ${ }^{4}$ At $37^{\circ} \mathrm{C}$ dissociation of the labile fraction appeared complete at 18 hours. At $22^{\circ} \mathrm{C}$ the fall in the percentage of haemoglobin $A_{1}$ at 18 and at 24 hours did not differ appreciably from the fall at $37^{\circ} \mathrm{C}$, whereas at $4^{\circ} \mathrm{C}$ no appreciable dissociation was seen.
In a larger study of 65 diabetic outpatients we took the magnitude of the difference in the percentage of haemoglobin $A_{1}$ as the difference between the percentage of haemoglobin $A_{1}$ measured after 18 hours' incubation in saline at $4^{\circ} \mathrm{C}$ and $22^{\circ} \mathrm{C}$. Blood was obtained by fingerprick, and two $50 \mu \mathrm{l}$ aliquots were added immediately to $1 \mathrm{ml}$ of $0.8 \%$ saline for subsequent measurement of percentage of haemoglobin $A_{1}$. A further aliquot was used for immediate estimation of blood glucose concentration. Percentage of haemoglobin $A_{1}$ was measured using both the microcolumn method and electroendosmosis (Corning Medical Ltd). Good agreement between these two methods has been shown in this laboratory. ${ }^{5}$

The figure shows the results of this study. Good agreement between the two methods was again seen. The difference in the percentage of haemoglobin $A_{1}$ was relatively small $(1.2 \pm S D 0.9 \%$, range -0.5 to 3.7 ; and $1.0 \pm 0.7 \%$, range -0.23 to 2.02 for the two methods respectively).

\section{Comment}

Our results confirm the presence of a reversibly bound labile component in the glycosylated haemoglobin fraction which can be removed by incubation in glucose-free medium for 18 hours at $22^{\circ} \mathrm{C}$. In the group of patients studied removal of this labile fraction produced a fall of approximately $1 \%$, determined by both methods of measurement, in the percentage of haemoglobin $A_{1}$, though just occasionally the difference was greater. This suggests that removal of the labile fraction does not appreciably improve the clinical value of the results and does not justify the time and cost incurred in the additional manipulation of samples.

Measurement of the percentage of haemoglobin $A_{1}$ is at its most useful in the diabetic clinic, when the result is available at the time that the patient is seen. Time spent in removing the labile fraction would preclude the availability of the result at the time of consultation, and the benefits obtained would not, in our opinion, justify the extra cost and effort. This immediate availability of results is possible only 